\section{Porton lab will study fever virus}

by Eleanor Lawrence

THE new laboratory at the Microbiological Research Establishment, Porton Down, formally opened last week by Lord Godber, provides facilities unrivalled in Western Europe for the safe handling of the most dangerous viruses known.

The new facilities will be used first to study the Lassa fever virus, and the other haemorrhagic fever viruses which have mainly been discovered within the past ten years and are virtually untreatable.

Porton, with a long history of handling some of the most dangerous organisms known to man was the obvious location for such a centre. The new laboratory was started two years ago, and has been modelled on facilities at the Communicable Diseases Center at Atlanta, Georgia, which, until now, was the only laboratory considered sufficiently secure to handle the Lassa fever virus.

The first task of the laboratory will be to build up a bank of diagnostic sera against the rare haemorrhagic fevers, such as Bolivian and Congo haemorrhagic fevers, and other exotic tropical virus diseases, such as Marburg disease, that may be brought into the UK. It will also provide this facility for other European countries and, in conjunction with Atlanta, for the areas where these diseases are endemic.

Lassa fever (first recognised in Nigeria) seems to be one of the most virulent virus diseases yet discovered. The mortality in Europeans with diagnosed Lassa fever is around $48 \%$ (although it seems to be lower in the native Nigerian population). It is also one of the most infectious virus diseases known. Patients shed virus from all body secretions and through the respiratory tract, and specimens of blood and urine are heavily infected. When the virus is multiplied up in tissue culture or in experimental animals, the risk of infection is greatly magnified.

Apart from its primary use in dealing with the virulent tropical viruses which may be carried into the UK undetected at any time by people returning from abroad, the laboratory will undoubtedly be in demand from research workers wishing to carry out some of the more potentially dangerous genetic engineering experiments in which the DNA of bacteria or viruses is modified by the addition of foreign DNA from other bacteria, viruses or even higher animals. Professor Rohert Harris, the Director of Porton, said last week that he had been approached by the Ashby Committee and had argeed that the laboratory facilities could be placed at the

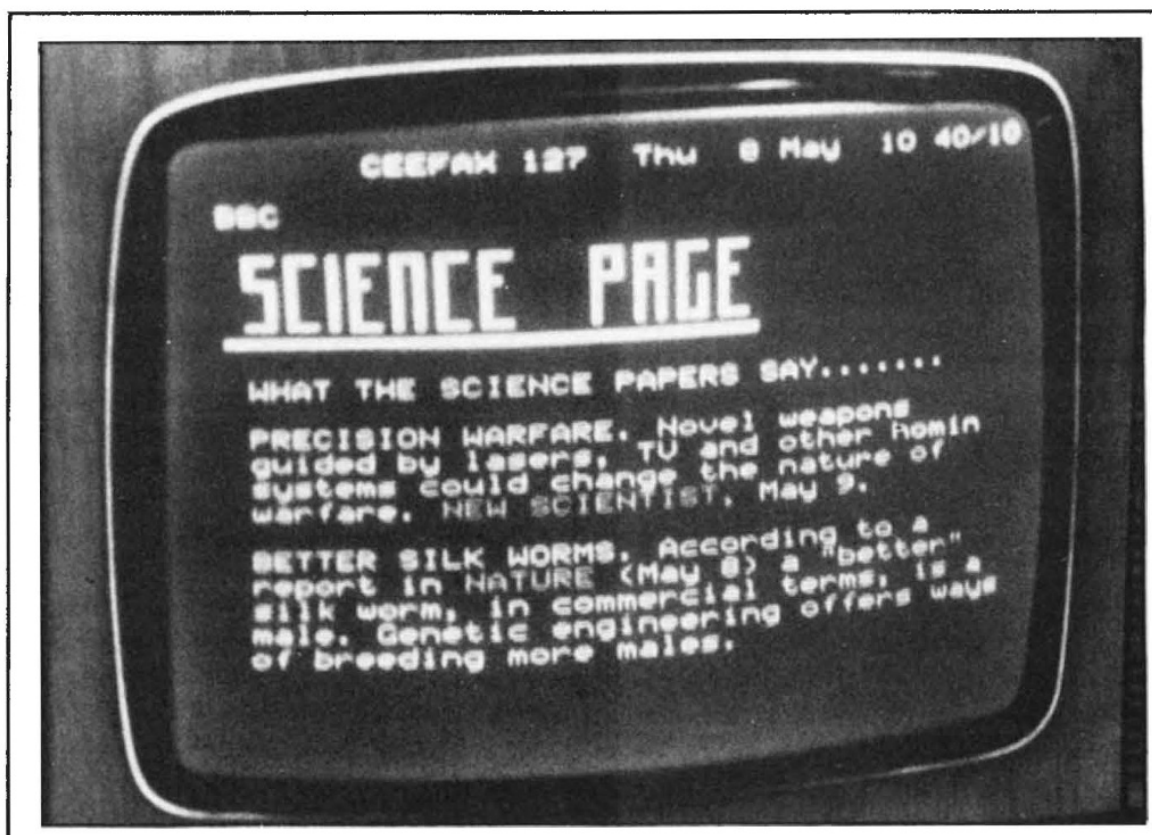

THE BBC has been providing at first they will be producing appropriate 24 and now 50 televised "pages" of decoders on a production-line basis by printed material by using spare lines early next year, when they should be in the ordinary BBC 1 TV channel available for about $£ 50$. A television since last September; the service set with such a decoder built in at the (code-named CEEFAX) is soon to be construction stage should then cost increased to 100 pages, and a similar about $£ 100$ more than an equivalent service (called Oracle, but using set without a decoder, and the inthe same standard technology as dustry hopes that prices will fall. CEEFAX) will be provided by the As well as newsflashes, sports reIndependent Broadcasting Authority sults, a science page (see above), (IBA) from next month. Until weather maps and other services recently, the cost of a decoder to already available from CEEFAX, this enable these printed words to be read new technology opens up intriguing on an ordinary television set has been possibilities. Using telephone links prohibitive-at least $£ 300$ for a and a keyboard, this kind of 'teletext' custom-made box of electronic tricks. could help to create a home computer But last week Texas Instruments, terminal, and there are obvious Bedford, announced in London that potential applications in education.

disposal of research workers wishing to undertake such experiments, but that he had not yet received any specific proposals. As the laboratory is sufficiently secure to satisfy the most stringent criteria set down by the recent conference called by Professor Paul Berg in California early this year, proposals will probably not be long in materialising.

The Berg conference recommended that experiments in which hybrids of two different viruses were made, or virus DNA (or DNA transcribed from RNA viruses) was linked to bacterial plasmids to multiply up virus genes, or mammalian DNA was linked to bacterial DNA could be carried out under conditions slightly less stringent than those in the new laboratory at Porton but that where the hybrid or the starting organisms were virulent or likely to prove so, the maximum security precautions should be taken. The other proviso of the Berg recommendations was that genetically enfeebled strains should be used.
But the prime object of the new facilities is the identification of the rare but virulent tropical viruses, which pose not just a potential but an actual public health hazard. With aeroplanes bringing their human and animal cargo into European airports every day from the tropics, the possibility of an epidemic of one of these virulent untreatable viruses cannot be discounted.

The only specific therapy which has proved effective against Lassa fever is serum taken from a convalescent patient. But with only three Europeâns having recovered from the disease, the supply of convalescent serum is extremely limited. Also, administering convalescent serum from a newly recovered patient can be extremely risky as virus is excreted from the patient for several weeks after clinical recovery. One aim at Porton is to establish a bank of safe serum, either from convalescent patients or from the naturally resistant native population, which can be given to patients once the disease has been diagnosed. 